\title{
Comparison of coronary artery calcification scores and National Cholesterol Education Program guidelines for coronary heart disease risk assessment and treatment paradigms in individuals with chronic traumatic spinal cord injury
}

\author{
Jesse A. Lieberman, Flora M. Hammond, Thomas A. Barringer, H. J. Norton, \\ David C. Goff, Jr, William L. Bockenek, William M. Scelza
}

Physical Medicine and Rehabilitation, Charlotte, NC, USA

Objective: To investigate the risk of coronary heart disease (CHD) in individuals with spinal cord injury (SCl) according to the National Cholesterol Educational Program (NCEP) guidelines and CT coronary artery calcium scores (CCS).

Research: Cross-sectional study of consecutive sample of males with $\mathrm{SCl}$ presenting to a single site for CHD risk assessment.

Participants/methods: Males age 45-70 with traumatic SCI (American Spinal Injury Association (ASIA) A, B, and $\mathrm{C}$ ) injured for at least 10 years with no prior history of clinical CHD. Medical history, blood-pressure, and fasting lipid panel were used to calculate risk for CHD with the use of the Framingham risk score (FRS). Risk and treatment eligibility status was assessed based on NCEP/FRS recommendations and by presence and amount of CCS. Percent agreement (PA) and kappa were calculated between the two algorithms. Spearman correlations were calculated between CCS and FRS and individual risk factors.

Results: A total of 38 men were assessed; $18(47.4 \%)$ had CCS $>0$. The PA between NCEP/FRS assessment and CCS was $18 \%$ with a kappa of -0.03 . 11 (28.9\%) had CCS $>100$ or $>75$ th percentile for their age, sex, and race, which might qualify them for lipid-lowering treatment. Only 26 were placed into the same treatment category by NCEP/FRS and CCS, for a PA of 68\% with a kappa of 0.35 . In all, 20 (52.6\%) were eligible for lipid-lowering treatment by either NCEP/FRS $(n=9)$ or CCS $(n=11)$. Seven subjects were above the treatment threshold based on CCS, but not NCEP/FRS and five subjects were above the NCEP/FRS threshold, but not CCS. Just four subjects were eligible by both algorithms. CCS only correlated with FRS $(r=0.508, P=0.001)$ and age $(r=0.679, P<0.001)$.

Keywords: Spinal cord injury, Coronary heart disease, Coronary artery calcium score, Framingham risk score

\section{Introduction}

Coronary heart disease (CHD) has emerged as a major cause of mortality in persons with chronic spinal cord injury (SCI), causing or contributing to $22.4 \%$ of all deaths in this population. ${ }^{1,2}$ Studies investigating the prevalence of CHD in the SCI population are limited, but one found a prevalence of $17 \%$ compared to $7 \%$ in

Correspondence to: Jesse A. Lieberman, Physical Medicine and Rehabilitation, Carolinas Rehabilitation, 1100 Blythe Boulevard, Charlotte, NC 28203, USA. E-mail: Jesse.Lieberman@Carolinashealthcare.org age matched controls. ${ }^{3}$ Individuals with SCI have also been demonstrated to be at increased risk of prematurely developing CHD. ${ }^{4,5}$ This is most likely because several cardiovascular disease (CVD) risk factors are more prevalent in individuals with chronic SCI compared to age, gender, and race matched able-bodied individuals. These factors include abnormalities of lipid metabolism, ${ }^{6,7}$ glucose intolerance/diabetes, ${ }^{8-10}$ obesity, ${ }^{11,12}$ lack of physical fitness, ${ }^{13,14}$ highly sensitive C-reactive protein, ${ }^{10,13,15}$ and other markers of inflammation and 
endothelial activation. ${ }^{16}$ High blood pressure is not more common in SCI and may be less common in some subgroups. ${ }^{17-19}$ Despite the increased risk for CHD, insufficient data guides decisions regarding prevention, screening, and treatment for individuals with SCI, especially with respect to management of dyslipidemia.

Currently, the National Cholesterol Education Program (NCEP) guidelines recommend use of the Framingham risk score (FRS) for CHD risk assessment of individuals in the USA. Risk assessment is based on the individual's cholesterol (total cholesterol (TC) and high-density lipoprotein-cholesterol (HDL-C)), age, sex, smoking history, blood pressure level and treatment status, family history, and presence of diabetes. ${ }^{20}$ The FRS is a multivariable model derived from research done in the general population and is the method most commonly used by practitioners to estimate CHD risk. ${ }^{21}$ However, prediction models that utilize traditional risk factors have great limitations in the individual patient, primarily due to not incorporating various other important risk factors, such as obesity, diet quality, activity level, markers of inflammation, etc. Several studies have demonstrated that the FRS applied to certain populations does not accurately estimate risk of CHD. ${ }^{22-24}$ The application of the FRS may not be appropriate in persons with $\mathrm{SCI}^{9,10,25}$; however, relatively little is known about the performance of the FRS in the SCI population.

CT coronary artery calcium scoring (CCS) is a noninvasive measure of subclinical atherosclerosis. CCS has been demonstrated in various populations to have excellent predictive ability in regard to both CHD events and total mortality. ${ }^{26-28}$ The consistency of these study results prompted the American Heart Association and the American College of Cardiology to issue consensus statements on the role of CCS in cardiovascular risk assessment. Their conclusions are that assessment of CCS is useful for the intermediate risk patient, and adds incremental value in predicting risk of a CHD event. ${ }^{29,30}$

Only one study has examined CCS in the SCI population, and this study did not report FRS or compare risk assessment between the NCEP approach and $\mathrm{CCS}^{31}$ Whether CCS is feasible and improves risk classification derived from the FRS has not been examined in an SCI population. This study is the first to compare risk assessment from the FRS and NCEP to CCS in a representative SCI sample. In this study, we assessed the prevalence and amount of coronary calcium. We then compared two risk stratification algorithms to determine whether treatment recommendations that might be based on CCS agreed with the NCEP guidelines. If disagreement regarding $\mathrm{CHD}$ risk and treatment eligibility is common in the SCI sample, a strong argument might be made for formal evaluation of the utility of this imaging modality as a screening tool for appropriate persons with SCI.

\section{Methods \\ Participants}

In this cross-sectional study, we enrolled 45 men, aged 45-70 years, with traumatic spinal cord injuries of at least 10 years. They were all American Spinal Injury Association (ASIA) A, B, or C. ${ }^{32}$ They could not have had any previous history of coronary artery disease. They were recruited with letters sent to their homes and fliers in our outpatient clinic. All participants gave their informed written consent, and the local institutional review board and research review committee approved the study

\section{Risk factors and risk equivalents assessment}

Each participant filled out an intake sheet regarding $\mathrm{CHD}$ risk equivalents and risk factors as defined by NCEP guidelines. Risk equivalents included clinical CHD, symptomatic carotid artery disease, diabetes, peripheral vascular disease, and abdominal aortic aneurysm. Risk factors included age, smoking history (defined as any cigarette smoking in the last month), family history of premature CHD (CHD in first degree male relative aged $<55$ years, or first degree female relative aged $<65$ years), and hypertension $(\mathrm{BP} \geq 140 / 90, \quad \text { or antihypertensive medication })^{20}$ (Table 1). This information was verified by examining their chart and measuring their blood pressure.

Additionally, subjects with SCI were assessed for 'duration of injury' (in years) and neurologic injury level. Injury level was defined as the first spinal vertebral

Table 1 CHD risk equivalents and risk factors as defined by the NCEP guidelines

\begin{tabular}{|c|c|}
\hline Risk equivalents & Criterion \\
\hline \multicolumn{2}{|l|}{ Clinical CHD } \\
\hline $\begin{array}{l}\text { Symptomatic carotid } \\
\text { artery disease }\end{array}$ & $\begin{array}{l}\text { Syncope, TIA, or stroke with }>50 \% \\
\text { stenosis }\end{array}$ \\
\hline $\begin{array}{l}\text { Peripheral vascular } \\
\text { disease }\end{array}$ & $\begin{array}{c}\mathrm{ABI}<0.9 \text {, lower limb blood flow } \\
\text { studies, or clinical symptoms }\end{array}$ \\
\hline Abdominal aortic aneurysm & \\
\hline $\begin{array}{l}\text { Diabetes mellitus } \\
\text { Risk factors }\end{array}$ & Type I or type II \\
\hline $\begin{array}{l}\text { RISk tactors } \\
\text { Age }\end{array}$ & Men $>45$ \\
\hline Smoking history & Any smoking history in the last month \\
\hline Hypertension & $\begin{array}{l}\mathrm{BP}>140 / 90, \text { or antihypertensive } \\
\text { medication }\end{array}$ \\
\hline Family history & $\begin{array}{l}\text { Premature } \mathrm{CHD} \text { (in male first-degree } \\
\text { relative }<55 \text { years, } \mathrm{CHD} \text { in female } \\
\text { first-degree relative }<65 \text { years) }\end{array}$ \\
\hline
\end{tabular}


level consistent with abnormal neurologic loss (i.e. C2-C8, T1-T12, L1-L5, and S1-S5) and also as complete or incomplete. Complete injury, or ASIA A, was defined as no motor or sensory function in the anal and perineal region representing the lowest sacral (S4-S5) cord; incomplete injury, or ASIA B and C was defined as either sensory incomplete or motor incomplete, respectively. ${ }^{32}$

\section{Lipid profiles}

Venous blood samples were taken after an overnight fast. TC and triglycerides (TG) were determined using an enzymatic colorimetric test and HDL-C using a homogeneous enzymatic colorimetric test (Beckman Coulter). For participants with TG less than $400 \mathrm{mg} / \mathrm{dL}$, lowdensity lipoprotein cholesterol (LDL-C) values were determined using the Friedewald equation. ${ }^{33}$

\section{Framingham risk score}

The FRS was calculated using the risk assessment tool on the NCEP website: http://hp2010.nhlbihin.net/ atpiii/calculator.asp. Lipid profiles (TC, HDL-C) and risk factors (age, gender, systolic blood pressure, current medication use for hypertension, and smoking history) are used in the calculation. The score represents an individual's 10-year risk of having a CHD event.

\section{NCEP risk assessment}

Following the NCEP guidelines, we used the LDL-C, presence of CHD risk equivalents, and the FRS to estimate an individual's risk of developing CHD. Participants were assigned to one of four risk categories on the basis of the recommendations provided in ATP III regardless of their lipid-lowering therapy status. The four risk categories were as follows: (1) low risk, defined as 0-1 risk factor for CHD; (2) intermediate low risk, defined as $\geq 2$ risk factors and an FRS $<10 \%$; (3) intermediate high risk, defined as $\geq 2$ risk factors and an FRS of 10-20\%; and (4) high risk, defined as CHD risk equivalent, or an FRS $>20 \%$. Participants were classified according to NCEP-based lipid-lowering drug treatment eligibility based on whether their LDL-C concentration exceeded the risk group-specific treatment initiation thresholds recommended in ATP III: > 190, 160, 130, and $100 \mathrm{mg} / \mathrm{dl}$ for risk groups 1-4, respectively. Participants on a lipid-lowering drug were presumed to have qualified for treatment.

\section{Coronary artery calcium scores}

A 64-row multi-detector computed tomography (MDCT) scanner was used to image the heart and assess CCS. This assessment was performed as a gated examination with helical acquisition utilizing ECG pulsing to reduce radiation dose using a Siemans collimator $(24 \times 1.2 \mathrm{~mm}(64)$ and $16 \times 1.5(16))$ with 0.24 pitch and 0.37 second rotation time. Typical scan time was 8 seconds using $120 \mathrm{kVp}$ at $300 \mathrm{mAs}$ technique. Images were reconstructed at $3 \mathrm{~mm}$ thick $\times 1.5$ increments with reconstruction kernel B35f Heartview medium and the mediastinal window. The participants held their breath for 5-10 seconds while the scan was performed (for individuals on a ventilator the ventilator was managed to accomplish this). Scoring of coronary calcium was automated by the CT scanner software, and studies have shown high reproducibility. ${ }^{34}$ Each CT scan was then read by a radiologist for incidental findings.

The multi-ethnic study of atherosclerosis (MESA) CCS reference value web tool was used to determine each individual's CCS percentile based on their CCS, age, and race. MESA, ${ }^{35}$ sponsored by the National Heart Lung and Blood Institute of the National Institutes of Health, is a study of the characteristics of subclinical CVD (disease detected non-invasively before it has produced clinical signs and symptoms) and the risk factors that predict progression to clinically overt CVD. The MESA database included a diverse, population-based sample of 6500 asymptomatic men and women, ages 45-84 years at the initial examination. Approximately $40 \%$ of the recruited participants were white, 30\% African-American, 20\% Hispanic, and 10\% Asian, predominantly of Chinese descent.

The MESA CCS reference values web tool provided the estimated probability of non-zero calcium, and the 25th, 50th, 75th, and 90th percentiles of the CCS distribution for a particular age, gender, and race. Additionally, the program provided the estimated percentile for the individual's CCS. At the time of this study, the risk associated with a particular calcium score was unknown. Thus, the information provided by this tool could not be used to conclude definitively that a patient was at 'high risk', but could be used to indicate whether they had a high CCS relative to others with the same age, gender, and race/ethnicity. For this analysis, we defined CCS-based 'high risk' as CCS $>400$ or $\geq 75$ th percentile for age, sex, and race. Intermediate high risk was defined as individuals with CCS 101-400 and <75th percentile for age, sex, and race; intermediate low risk as others with CCS 1-100 and $<75$ th percentile for age, sex, and race; and low risk as $\mathrm{CCS}=0$. These risk classification categories have been used in the general population. ${ }^{36,37}$ Participants were classified according to CCS-based lipid-lowering drug treatment eligibility based on 
whether their LDL-C concentration exceeded the risk group-specific treatment initiation thresholds recommended in ATP III applied to the CCS risk categories: >190, 160, 130, and $100 \mathrm{mg} / \mathrm{dl}$ for risk groups $1-4$, respectively. Participants on a lipid-lowering drug were presumed to have qualified for treatment.

\section{Data analysis}

Variables were described using means, standard deviations, and percentages; 95\% confidence intervals were calculated for the comparison of the proportion of individuals in this study with $\mathrm{CCS}>0$ compared to those reported in MESA (49.9\%). ${ }^{35}$ Spearman's correlation coefficients were calculated between CCS, FRS, cholesterol, systolic blood pressure, number of risk factors, level of injury, and duration of injury. Both the NCEP/FRS and CCS-based risk and treatment eligibility classification algorithms were used separately to place each subject into one of the four risk classification categories (i.e. high risk, intermediate high risk, etc.) Agreement between the NCEP/FRS and CCS-based algorithms was examined by estimating percent agreement (PA) and kappa. The PA was defined as the total number of subjects who were classified into either the same risk or treatment classification category by both the NCEP/FRS and CCS algorithms divided by the total number of subjects (i.e. the total number of subjects classified high risk by both algorithms, plus the total number classified intermediate high risk by both algorithms, plus the total number classified intermediate low risk by both algorithms, plus the total number classified low risk by both algorithms, divided by the total number of subjects). The kappa statistic measures the agreement between two ratings that is beyond the role of chance. A kappa of zero indicates the observed agreement between the two risk assessment tools is due to chance, while a kappa of 1 would indicate there is complete agreement. ${ }^{38}$ The subjects whose CCS placed them in either a higher risk classification category or lower risk classification category compared to their NCEP/FRS category were considered either 'up classified' or 'down classified,' respectively. This technique has been described by Pencina et al. ${ }^{39} \mathrm{~A}$ $P$-value $<0.05$ was considered statistically significant; SAS, version 9.1, software was used for all analyses.

\section{Results}

Demographics

A total of 45 males with traumatic spinal cord injuries were enrolled. Three were later excluded: one completed the study, but was later found to be ineligible and the other two were excluded before they underwent any testing. Four individuals withdrew from the study: one had concerns regarding the radiation from the CT scan, and the other three decided they did not want to be in the study for undisclosed reasons. The remaining 38 individuals' data were analyzed. 9 of the $38(23.7 \%)$ were on lipid-lowering treatment. The descriptive characteristics of the individuals who completed the study are shown in Table 2.

\section{Coronary artery calcium scores}

The distribution of CCS by NCEP category and the compliance with NCEP guidelines is shown in Table 3. A total of 18 of the 38 individuals $(47.4 \%, 95 \%$ confidence interval (CI) of 31.0-64.2\%) had CCS $>0$. Overall, 23 individuals were 'down classified' by their CCS scores and 8 individuals were 'up classified' by their CCS scores. The PA between the NCEP risk assessment and the CCS risk assessment was $18 \%$. The PA by chance was $21 \%$ and the kappa was -0.03. 11 $(28.9 \%, 95 \%$ CI of $15.4-45.9 \%)$ had CCS scores $>101$

Table 2 Descriptive characteristics of study participants

\begin{tabular}{ll}
\hline Characteristics & Values \\
\hline Eligible subjects who completed the full study & 38 \\
Non-Hispanic whites & 31 \\
African-Americans & 7 \\
Asians/Hispanics/native Americans/other & 0 \\
Tetraplegics & $21(55.3 \%)$ \\
Paraplegics & $17(44.7 \%)$ \\
ASIA classification & $16(42.1 \%)$ \\
A & $16(42.1 \%)$ \\
B & $6(15.8 \%)$ \\
C & $55.0+7.2$ \\
Mean age + SD (years) & $24.4+9.5$ \\
Time since injury + SD (years) &
\end{tabular}

Table 3 Risk classification by CCS and NCEP/FRS algorithms

\begin{tabular}{|c|c|c|c|c|c|}
\hline \multirow[b]{2}{*}{$\begin{array}{l}\text { CCS risk } \\
\text { categories }\end{array}$} & \multicolumn{4}{|c|}{ NCEP/FRS risk categories } & \multirow[b]{2}{*}{ Total } \\
\hline & Low & $\begin{array}{l}\text { Intermediate } \\
\text { low }\end{array}$ & $\begin{array}{l}\text { Intermediate } \\
\text { high }\end{array}$ & High & \\
\hline $\mathrm{CCS}=0$ & 3 & 12 & 3 & 2 & 20 \\
\hline $\begin{array}{l}\text { CCS }= \\
1-100 \\
<75 \text { th } \\
\text { percentile }\end{array}$ & 1 & 0 & 3 & 3 & 7 \\
\hline $\begin{array}{l}\text { CCS }= \\
101-400 \\
<75 \text { th } \\
\text { percentile }\end{array}$ & 0 & 1 & 1 & 0 & 2 \\
\hline $\begin{array}{l}\text { CCS }= \\
>400, \text { or } \\
>75 \text { th } \\
\text { percentile }\end{array}$ & 1 & 2 & 3 & 3 & 9 \\
\hline Total & 5 & 15 & 10 & 8 & 38 \\
\hline
\end{tabular}


or $\geqslant 75$ th percentile for their age, sex, and race placing them in either the intermediate high risk or high risk category. However, 4 of the 11 were considered low or intermediate low risk by their NCEP risk assessment. Of the 18 classified as intermediate high risk or high risk by NCEP criteria, only 7 were in those categories by their CCS. Finally, 9 of $38(23.7 \%, 95 \%$ CI of $11.4-40.2 \%$ ) had CCS $>400$ or $\geqslant 75$ th percentile for their age, race and gender, indicating a very high risk of a CHD event, yet only 3 of these participants were classified as high risk by NCEP criteria.

We further examined the proportion who qualified for treatment based on CCS and NCEP/FRS algorithms (Table 4). Only 26 of the 38 , resulting in a PA of $68 \%$, were placed into the same treatment categories by both CCS and NCEP/FRS algorithms. The PA due to chance was $51 \%$ and the kappa for treatment classification was 0.35 . Of the 11 deemed eligible for treatment by CCS, only $4(36.4 \%)$ were also deemed eligible by NCEP/FRS.

We examined the treatment of the nine individuals in the CCS-based high risk category as CHD risk equivalents (Table 5); five had LDL-C $>100 \mathrm{mg} / \mathrm{dl}$,

Table 4 Eligibility for treatment by CCS and NCEP/FRS algorithms

\begin{tabular}{lccc}
\hline & \multicolumn{2}{c}{ NCEP/FRS treatment categories } & \\
\cline { 2 - 3 } $\begin{array}{l}\text { CCS treatment } \\
\text { categories }\end{array}$ & $\begin{array}{c}\text { Above treatment } \\
\text { threshold }\end{array}$ & $\begin{array}{c}\text { Not } \\
\text { eligible }\end{array}$ & Total \\
\hline $\begin{array}{l}\text { Above treatment } \\
\quad \text { threshold }\end{array}$ & 4 & 7 & 11 \\
Not eligible & 5 & 22 & 27 \\
Total & 9 & 29 & 38 \\
\hline
\end{tabular}

Table 5 LDL treatment and control in high-CCS ( $>400$ or $>75$ th $\%$ ) individuals with $\mathrm{SCI}$

\begin{tabular}{|c|c|c|c|c|c|}
\hline Ccs & $\begin{array}{c}\text { CCS } \\
\text { percentile } \\
\text { from MESA } \\
\text { reference } \\
\text { tool }\end{array}$ & LDL & $\begin{array}{l}\text { Original FRS } \\
\text { category }\end{array}$ & $\begin{array}{l}\text { Lipid } \\
\text { lowering } \\
\text { treatment }\end{array}$ & $\begin{array}{l}\text { LDL-C } \\
<100\end{array}$ \\
\hline 422 & 80 & 79 & Low & Yes & Yes \\
\hline 99 & 78 & 158 & $\begin{array}{l}\text { Intermediate } \\
\text { low }\end{array}$ & No & No \\
\hline 46 & 86 & 69 & $\begin{array}{l}\text { Intermediate } \\
\text { low }\end{array}$ & No & Yes \\
\hline 450 & 89 & 112 & $\begin{array}{l}\text { Intermediate } \\
\text { high }\end{array}$ & No & No \\
\hline 412 & 94 & 48 & $\begin{array}{l}\text { Intermediate } \\
\text { high }\end{array}$ & No & Yes \\
\hline 144 & 86 & 143 & $\begin{array}{l}\text { Intermediate } \\
\text { high }\end{array}$ & No & No \\
\hline 415 & 78 & 113 & High & Yes & No \\
\hline 252 & 84 & 103 & High & Yes & No \\
\hline 1049 & 98 & 93 & High & No & Yes \\
\hline
\end{tabular}

thereby potentially qualifying for drug treatment or intensification, and only two of the five were on lipidlowering drug therapy. One additional participant was on lipid-lowering drug therapy with an LDL-C $<$ $100 \mathrm{mg} / \mathrm{dl}$.

\section{Relationship between coronary artery calcium scores and individual characteristics}

Spearman correlation coefficients were estimated between CCS and individual characteristics, including duration of injury, level of injury, number of risk factors, FRS, HDL-C, as well as systolic blood pressure, TC, TG, and LDL-C. Only FRS $(r=0.508, P=0.001)$ and age $(r=0.679, P<0.001)$ demonstrated significant correlation. None of the other characteristics including duration of injury $(r=0.000, P=0.999)$, number of risk factors $(r=0.190, P=0.254)$, level of injury $(r=$ $0.138, P=0.409)$, HDL-C $(r=0.120, P=0.475)$, systolic blood pressure $(r=0.130, \quad P=0.438), \quad$ TC $(r=-0.049, P=0.770)$, TG $(r=-0.034, P=0.842)$, or LDL-C $(r=-0.133, P=0.427)$ demonstrated a significant correlation with CCS.

\section{Discussion}

CVD is a leading cause of death in individuals with chronic SCI, and CHD is responsible for a significant number of these deaths. Our report was consistent with previous findings that $\mathrm{CHD}$, as measured by $\mathrm{CCS}$, is common in individuals with chronic traumatic $\mathrm{SCI}^{31}$ In addition, our findings suggest that the inclusion of CCS with CHD risk factor assessment by FRS may improve the identification of individuals who may require intervention. Of 38 participants, 23 were 'down classified' by their CCS relative to the FRS-based algorithm, whereas eight were 'up classified'. Only 7 of the 38 were classified equivalently by the two risk assessment tools for a PA of $18 \%$ and a kappa of essentially zero, indicating that the observed agreement between the two risk assessment tools was due to chance. The PA between the treatment classification algorithms was somewhat better, but it was only $68 \%$ with a kappa of 0.35 , indicating poor agreement. Only $36.4 \%$ of participants who might qualify for treatment based on CCS also qualified for treatment based on the NCEP/FRS algorithm. These results indicate a substantial disagreement between the FRS-based risk and treatment eligibility classification algorithm recommended by the NCEP and the CCS-based algorithm examined in this sample of individuals with chronic SCI.

Due to lack of sensation and/or the ability to do strenuous activity, including activities such as household 
chores or walking, many individuals with SCI will not manifest typical exertional angina pectoris. Therefore diagnosing CHD prior to a cardiac event must be performed by screening asymptomatic individuals. Asymptomatic heart disease has been reported previously in individuals with chronic SCI undergoing coronary disease evaluation. Bauman et al. ${ }^{40,41}$ used thallium-201 myocardial perfusion imaging in small studies of people with tetraplegia and paraplegia to highlight the silent nature of this disease and the need to detect and control risk factors early. ${ }^{40,41}$ They found that participants in these studies had an average of five CHD risk factors. Among those with tetraplegia $(n=6)$, none had symptoms of ischemia, whereas four out of six demonstrated a thallium scintigraphy defect. Of those with paraplegia $(n=20), 5$ had symptoms of ischemia, whereas 13 (including the 5 with ischemia) demonstrated thallium scintigraphy defects. CCS has also been used in one other published study, which demonstrated an increased atherosclerotic burden in individuals with chronic SCI compared to able-bodied controls. They did not, however, assess whether these individuals met criteria for lipid-lowering drug treatment on the basis of their FRS, nor whether the CCS results would have altered their treatment after assessing their FRS. ${ }^{31}$

In our study, the number of traditional risk factors was not associated with CCS, although age as a single factor and the FRS, which is a composite of age and other risk factors, were associated with CCS. These findings may indicate that there are non-traditional factors, for example, inflammation, that may play a significant role in SCI patients. Recent studies have demonstrated that markers of inflammation and endothelial activation are elevated in individuals with SCI compared to ablebodied controls. ${ }^{16,42}$ Other possibilities include additional CHD risk factors that are not included directly in the FRS, such as glucose intolerance and abdominal obesity. ${ }^{8-10,12}$ The FRS algorithm includes both smoking status and TC; however, Krum et al. ${ }^{43}$ found that the increased risk of CHD in SCI compared to the able-bodied population cannot be explained by differences in TC or smoking. Currently there are not any clinically relevant, validated tools specifically developed to identify adults with SCI at risk for CHD. A valid and practical screening tool such as the FRS applicable to SCI patients could improve risk assessment in persons with SCI. ${ }^{25}$

The value of screening for CHD with CCS in the general population is still being determined. There are uncertainties with regard to how, when, and in whom the test should be performed, what CCS threshold should trigger more aggressive treatment of risk factors, and what the most appropriate treatment is once that threshold is crossed. ${ }^{44}$ Because of the minimal data on outcomes of individuals who have previously had CCS, CCS does not meet the criteria for population screening established by the US Preventive Services Task Force. ${ }^{45}$ Their criteria specify that screening and treating persons for early-onset disease should improve the likelihood of favorable health outcomes (e.g. reduced disease-specific morbidity or mortality), as compared with the treatment of patients when they present with signs or symptoms of the disease. In those categorized as having a low risk of coronary events according to the ATP III criteria, the presence of coronary calcium increases the risk of future events, but the likelihood of coronary events remains low. Similarly, for those in the high-risk category, the risk of an event is not precluded by a low CCS. Therefore, attention to risk reduction is warranted regardless of the CCS in high risk persons.

The group most likely to benefit from the additional risk stratification provided by measuring CCS is the intermediate risk group, that is, those with $2+$ risk factors and a 10-year risk of $<20 \% .{ }^{44}$ An absence of coronary calcium in these patients might shift them to a low-risk category with less need to treat, whereas a high CCS might indicate a higher level of risk that calls for more intensive treatment of modifiable risk factors. ${ }^{28,46}$ A scientific statement from the American Heart Association ${ }^{29}$ as well as an expert-consensus document from the American College of Cardiology and the American Heart Association ${ }^{30}$ conclude that it may be reasonable to consider CCS screening in asymptomatic persons identified as having an intermediate risk of coronary events. This view is based on the assumption that such patients with multiple risk factors will be reclassified in a higher risk group based on their CCS and that the management of risk factors will then be intensified. ${ }^{29}$ In our study, 25 of the 38 participants were in the intermediate risk category, and 10 had CCS $>0$, including 5 with CCS $>101$ and 2 with CCS $>400$, indicating substantial proportions whose treatment might be modified.

The major unresolved question is whether utilization of CCS screening will lead to an overall improvement in quality of care and clinical outcomes. Widespread CCS screening runs the risk of increasing the number of unnecessary tests and procedures downstream including stress imaging, coronary angiography, and revascularization interventions. These tests and procedures can contribute to escalating health care costs and carry their own risks. 
In addition, there are concerns regarding cancer risk from the radiation exposure associated with using CT to assess the CCS. ${ }^{47-50}$ The standard chest radiograph yields a radiation dose of $0.01-0.02 \mathrm{mSv}^{47,48}$ The usual radiation burden associated with CCS scanning is small as well but real (generally, $0.6-1.0 \mathrm{mSv}$ for EBCT and 0.9-2.0 mSv for MDCT). ${ }^{27}$ Some MDCT imaging protocols are associated with estimated radiation doses higher than $10 \mathrm{mSv}^{49}$ In the USA, the effective annual background radiation is $3.6 \mathrm{mSV}$, so the radiation from one CCS scan $(\sim 2.0 \mathrm{mSv})$ approximates to 6.5 months of the effective annual background radiation. ${ }^{51}$ An effective dose of $2.3 \mathrm{mSv}$ is estimated to result in a small measurable increase in the risk of cancer. ${ }^{49}$ Therefore, an individual's annual radiation exposure by way of geography, and clinical burden should be part of the consideration, when qualifying risk. This could become an even more important issue if CCS testing (and repeated testing) is used in widespread population screening.

Our study presents several limitations. This is only the second published study using CCS scoring in individuals with SCI. Therefore, it is not known if CCS correlates as well with CHD in the SCI population as in the ablebodied population. Our sample was small (38 individuals), all male, and comprised exclusively of African Americans and Caucasians. This small sample size could have limited our ability to detect correlations between CCS and traditional CHD risk factors. Further testing with a larger sample size may help identify risk factors beyond age and FRS. Women were excluded from this pilot study because they are underrepresented in the SCI population (ratio of men to women $4: 1)^{52}$; we would therefore have had too few women to draw meaningful conclusions. Additionally, the study was done at a single academic medical center in the southeastern USA. Therefore, a large, multicenter study encompassing multiple ethnicities and both genders will be needed to determine whether CCS may be useful in CHD risk assessment and treatment in the chronic SCI population.

\section{Conclusions}

CHD as measured by CCS is common in males aged 45-70 years with chronic traumatic SCI. CCS is associated with age and the FRS, but was not related to duration of injury, total number of risk factors, systolic blood pressure, lipids, or level of injury in this small sample. There is substantial disagreement between the NCEP/FRS risk and treatment eligibility assessments and potential CCS-based assessments in this population. Risk assessment as recommended in the NCEP guidelines may not estimate the risk of CHD accurately in individuals in the SCI population. CCS could be considered as an adjunct to routine CHD screening for intermediate risk individuals with chronic SCI if these results are confirmed by future studies.

\section{Acknowledgments}

This study was made possible by a grant from the Carolinas Healthcare System Health and Science Foundation.

The authors would like to acknowledge Marybeth Whitney, RN, BSN and Patty Aykroyd, CNA II for help in coordinating the study and assisting with data management.

\section{References}

1 DeVivo MJ, Kartus PL, Stover SL, Rutt RD, Fine PR. Cause of death for patients with spinal cord injuries. Arch Intern Med 1989;149(8):1761-6.

2 Whiteneck GG, Charlifue SW, Frankel HL, Fraser MH, Gardner BP, Gerhart KA, et al. Mortality, morbidity, and psychosocial outcomes of persons spinal cord injured more than 20 years ago. Paraplegia 1992;30(9):617-30.

3 Yekutiel M, Brooks ME, Ohry A, Yarom J, Carel R. The prevalence of hypertension, ischaemic heart disease and diabetes in traumatic spinal cord injured patients and amputees. Paraplegia 1989;27(1):58-62.

4 DeVivo MJ, Black KJ, Stover SL. Causes of death during the first 12 years after spinal cord injury. Arch Phys Med Rehabil 1993; 74(3):248-54.

5 Bauman WA, Spungen AM. Coronary heart disease in individuals with spinal cord injury: assessment of risk factors. Spinal Cord 2008;46(7):466-76.

6 Bauman WA, Adkins RH, Spungen AM, Kemp BJ, Waters RL. The effect of residual neurological deficit on serum lipoproteins in individuals with chronic spinal cord injury. Spinal Cord 1998; 36(1):13-17.

7 Bauman WA, Spungen AM, Zhong YG, Rothstein JL, Petry C, Gordon SK. Depressed serum high density lipoprotein cholesterol levels in veterans with spinal cord injury. Paraplegia 1992;30(10): 697-703.

8 Bauman WA, Adkins RH, Spungen AM, Waters RL. The effect of residual neurological deficit on oral glucose tolerance in persons with chronic spinal cord injury. Spinal Cord 1999;37(11):765-71.

9 Jones LM, Legge M, Goulding A. Factor analysis of the metabolic syndrome in spinal cord-injured men. Metab Clin Exp 2004;53(10): 1372-77.

10 Lee MY, Myers J, Hayes A, Madan S, Froelicher VF, Perkash I, et al. C-reactive protein, metabolic syndrome, and insulin resistance in individuals with spinal cord injury. J Spinal Cord Med 2005;28(1):20-5.

11 Kocina P. Body composition of spinal cord injured adults. Sports Med 1997;23(1):48-60.

12 Buchholz AC, Bugaresti JM. A review of body mass index and waist circumference as markers of obesity and coronary heart disease risk in persons with chronic spinal cord injury. Spinal Cord 2005;43(9):513-8.

13 Manns PJ, McCubbin JA, Williams DP. Fitness, inflammation, and the metabolic syndrome in men with paraplegia. Arch Phys Med Rehabil 2005;86(6):1176-81.

14 Buchholz AC, McGillivray CF, Pencharz PB. Physical activity levels are low in free-living adults with chronic paraplegia. Obes Res 2003;11(4):563-70.

15 Gibson AE, Buchholz AC, Martin Ginis KA. C-Reactive protein in adults with chronic spinal cord injury: increased chronic inflammation in tetraplegia vs paraplegia. Spinal Cord 2008;46(9): 616-21. 
16 Wang TD, Wang YH, Huang TS, Su TC, Pan SL, Chen SY. Circulating levels of markers of inflammation and endothelial activation are increased in men with chronic spinal cord injury. J Formosan Med Assoc 2007;106(11):919-28.

17 Groah SL, Weitzenkamp D, Sett P, Soni B, Savic G. The relationship between neurological level of injury and symptomatic cardiovascular disease risk in the aging spinal injured. Spinal Cord 2001; 39(6):310-7.

18 Teasell RW, Arnold JM, Krassioukov A, Delaney GA. Cardiovascular consequences of loss of supraspinal control of the sympathetic nervous system after spinal cord injury. Arch Phys Med Rehabil 2000;81(4):506-16.

19 Blackmer J. Orthostatic hypotension in spinal cord injured patients. J Spinal Cord Med 1997;20(2):212-7.

20 Third Report of the National Cholesterol Education Program (NCEP). Expert panel on detection, evaluation, and treatment of high blood cholesterol in adults (Adult Treatment Panel III) final report. Circulation 2002;106(25):3143-421.

21 Wilson PW, D'Agostino RB, Levy D, Belanger AM, Silbershatz H, Kannel WB. Prediction of coronary heart disease using risk factor categories. Circulation 1998;97(18):1837-47.

22 Michos ED, Vasamreddy CR, Becker DM, Yanek LR, Moy TF, Fishman EK, et al. Women with a low Framingham risk score and a family history of premature coronary heart disease have a high prevalence of subclinical coronary atherosclerosis. Am Heart J 2005;150(6):1276-81.

23 Michos ED, Nasir K, Rumberger JA, Vasamreddy C, Braunstein $\mathrm{JB}$, Budoff MJ, et al. Relation of family history of premature coronary heart disease and metabolic risk factors to risk of coronary arterial calcium in asymptomatic subjects. Am J Cardiol 2005; 95(5):655-7.

24 Akosah KO, Schaper A, Cogbill C, Schoenfeld P. Preventing myocardial infarction in the young adult in the first place: how do the National Cholesterol Education Panel III guidelines perform? J Am Coll Cardiol 2003;41(9):1475-9.

25 Finnie AK, Buchholz AC, Martin Ginis KA. Current coronary heart disease risk assessment tools may underestimate risk in community-dwelling persons with chronic spinal cord injury. Spinal Cord 2008;46(9):608-15.

26 Guerci AD. The prognostic accuracy of coronary calcification. J Am Coll Cardiol 2007;49(18):1871-3.

27 Budoff MJ, Shaw LJ, Liu ST, Weinstein SR, Mosler TP, Tseng PH, et al. Long-term prognosis associated with coronary calcification: observations from a registry of 25,253 patients. J Am Coll Cardiol 2007;49(18):1860-70.

28 Arad Y, Goodman KJ, Roth M, Newstein D, Guerci AD. Coronary calcification, coronary disease risk factors, C-reactive protein, and atherosclerotic cardiovascular disease events: the St. Francis Heart Study. J Am Coll Cardiol 2005;46(1):158-65.

29 Budoff MJ, Achenbach S, Blumenthal RS, et al. Assessment of coronary artery disease by cardiac computed tomography: a scientific statement from the American Heart Association Committee on Cardiovascular Imaging and Intervention, Council on Cardiovascular Radiology and Intervention, and Committee on Cardiac Imaging, Council on Clinical Cardiology. Circulation 2006;114(16):1761-91.

30 Greenland P, Bonow RO, Brundage BH, Budoff MJ, Eisenberg MJ, Grundy SM, et al. ACCF/AHA 2007 clinical expert consensus document on coronary artery calcium scoring by computed tomography in global cardiovascular risk assessment and in evaluation of patients with chest pain: a report of the American College of Cardiology Foundation Clinical Expert Consensus Task Force (ACCF/AHA Writing Committee to Update the 2000 Expert Consensus Document on Electron Beam Computed Tomography) developed in collaboration with the Society of Atherosclerosis Imaging and Prevention and the Society of Cardiovascular Computed Tomography. J Am Coll Cardiol 2007;49(3):378-402.

31 Orakzai SH, Orakzai RH, Ahmadi N, et al. Measurement of coronary artery calcification by electron beam computerized tomography in persons with chronic spinal cord injury: evidence for increased atherosclerotic burden. Spinal Cord 2007;45(12):775-9.
32 Marino RJ, Barros T, Biering-Sorensen F, Burns SP, Donovan $\mathrm{WH}$, Graves DE, et al. International standards for neurological classification of spinal cord injury. J Spinal Cord Med 2003; 26(Suppl 1):S50-6.

33 Friedewald WT, Levy RI, Fredrickson DS. Estimation of the concentration of low-density lipoprotein cholesterol in plasma, without use of the preparative ultracentrifuge. Clin Chem 1972; 18(6):499-502.

34 Detrano RC, Anderson M, Nelson J, Wong ND, Carr JJ, McNittGray M, et al. Coronary calcium measurements: effect of CT scanner type and calcium measure on rescan reproducibility MESA study. Radiology 2005;236(2):477-84.

35 Bild DE, Detrano R, Peterson D, Guerci A, Liu K, Shahar E, et al. Ethnic differences in coronary calcification: the Multi-Ethnic Study of Atherosclerosis (MESA). Circulation 2005;111(10): 1313-20.

36 Pletcher MJ, Tice JA, Pignone M, Browner WS. Using the coronary artery calcium score to predict coronary heart disease events: a systematic review and meta-analysis. Arch Intern Med 2004; 164(12):1285-92.

37 Arad Y, Spadaro LA, Roth M, Newstein D, Guerci AD. Treatment of asymptomatic adults with elevated coronary calcium scores with atorvastatin, vitamin $\mathrm{C}$, and vitamin E: the St. Francis Heart Study randomized clinical trial. J Am Coll Cardiol 2005; 46(1):166-72.

38 Cohen J. A coefficient of agreement for nominal scales. Educ Psychol Manage 1960;20(1):37-46.

39 Pencina MJ, D'Agostino RB, Vasan RS. Review: statistical methods for assessment of added usefulness of new biomarkers. Clin Chem Lab Med 2010;48:1703-11.

40 Bauman WA, Raza M, Spungen AM, Machac J. Cardiac stress testing with thallium-201 imaging reveals silent ischemia in individuals with paraplegia. Arch Phys Med Rehabil 1994;75(9): 946-50.

41 Bauman WA, Raza M, Chayes Z, Machac J. Tomographic thallium-201 myocardial perfusion imaging after intravenous dipyridamole in asymptomatic subjects with quadriplegia. Arch Phys Med Rehabil 1993;74(7):740-4.

42 Manns PJ, McCubbin JA, Williams DP. Fitness, inflammation, and the metabolic syndrome in men with paraplegia. Arch Phys Med Rehabil 2005;86(6):1176-81.

43 Krum H, Howes LG, Brown DJ, et al. Risk factors for cardiovascular disease in chronic spinal cord injury patients. Paraplegia 1992;30(6):381-8.

44 Bonow RO. Clinical practice. Should coronary calcium screening be used in cardiovascular prevention strategies? N Engl J Med 2009;361(10):990-7.

45 US Preventive Services Task Force. Guide to clinical preventive services. 2nd ed. 2010. http://odphp.osophs.dhhs.gov/pubs/ guidecps/PDF/Frontmtr.PDF. Accessed on 12-15-09.

46 Greenland P, LaBree L, Azen SP, Doherty TM, Detrano RC. Coronary artery calcium score combined with Framingham score for risk prediction in asymptomatic individuals. JAMA 2004; 291(2):210-5.

47 Brenner DJ, Hall EJ. Computed tomography-an increasing source of radiation exposure. N Engl J Med 2007;357(22):2277-84.

48 Fazel R, Krumholz HM, Wang Y, Ross JS, Chen J, Ting HH, et al. Exposure to low-dose ionizing radiation from medical imaging procedures. N Engl J Med 2009;361(9):849-57.

49 Kim KP, Einstein AJ, de Berrington GA. Coronary artery calcification screening: estimated radiation dose and cancer risk. Arch Intern Med 2009;169(13):1188-94.

50 Lauer MS. Elements of danger - the case of medical imaging. N Engl J Med 2009;361(9):841-3.

51 Idaho State University. Radioactivity in Nature Website [accessed 10-1-2010]. Available from: http://www.physics.isu.edu/radinf/ natural.htm.

52 National Spinal Cord Injury Statistical Center. Spinal Cord Injury Facts \& Figures at a Glance 2009 [updated 2009 June; accessed 2010 Mar 25]. Available from: http://www.fscip.org/ facts.htm. 